\title{
Article \\ Discursive Space and Its Consequences for Understanding Knowledge and Information
}

\author{
Rafal Maciag \\ Institute of Culture, Jagiellonian University, Krakow 30-348, Poland; rafal.maciag@uj.edu.pl
}

Received: 29 August 2018; Accepted: 29 October 2018; Published: 31 October 2018

check for updates

\begin{abstract}
The paper develops the idea of discursive space by describing the manner of existence of this space and the world of facts. The ontology of discursive space is based on the idea of discourse by Foucault. Discourse, being a language phenomenon, is a form of existence of knowledge. The discursive space is a representation of knowledge and can be interpreted as the system of acquiring this knowledge. This space is connected with the world of facts by a relationship of supervenience, which can be interpreted as a flow of knowledge. At the same time, the existence of the world of facts (world of affairs) assumes that it covers all phenomena and processes, and therefore, necessarily, also the discursive space. Hence, this space is not a separate system but a system that emerges from the world in order to allow the gathering of specific knowledge about it. Treating the discursive space as one of the possible cognitive systems, one can imagine other systems of knowledge that emerge from the world (the whole), as parts subordinated to particular goals (the use of knowledge), which can have a multilevel character. The flow of knowledge on the border of such a system and the whole of it can be interpreted as information. This paper tries to justify this possibility, which could lead to a general model of the flow of the knowledge.
\end{abstract}

Keywords: discourse; discursive space; information; knowledge; humanistic management; language

\section{Introduction}

This paper is a continuation and development of the theses presented in a text published in January 2018 [1]. The concept of discursive space as a complex space of knowledge has been presented and justified there as dynamic space, the concept of which has been borrowed from physics $[2,3]$. Discourses (discourses), being a common knowledge representation, traverse the trajectories in that space, the dimensions of which are qualitative and arbitrary. The concept of discourse and justification for its complex character was based on the theory of Michel Foucault [4-6]. The support for using the dynamic space model for the description of quality phenomena was provided by Byrne and Callaghan [7].

In this text, I try to develop the presented idea. This intention has two phases; firstly, it consists of supplementing the idea of a discursive space with a description of the necessary and assumed world, called the world of facts. Secondly, the idea of a mutual relationship between the world of facts and the space of discourses can lead to further conclusions that concern an important and interesting descriptive construction of knowledge and, perforce, information. The second phase is necessarily just the opening of a certain reasoning and is limited to the formulation of initial statements. Of course, according to Popper's classic approach, such statements must then be subjected to a critical check. Popper describes this process as follows: "From a new idea, put up tentatively, and not yet justified in any way-an anticipation, a hypothesis, a theoretical system, or what you will—conclusions are drawn by means of logical deduction. These conclusions are then compared with one another and with other relevant statements, so as to find what logical relations (such as equivalence, derivability, compatibility, or incompatibility) exist between them" [8] (p. 9). In the next paragraph, he points out 
four ways how practically the testing of the theory could be carried out. This paper executes this part of the scientific process that Popper called "the new idea" and its first steps, which stops shortly before the formal formulation of the hypothesis, preparing some of its premises. An analysis of the empirical phenomenon (e.g., the Internet) is taken as a starting point for the generalization that appears as possible to perform. This generalization is not an end in itself, but a necessary consequence of earlier reasoning. It cannot be omitted in this situation, especially since the area it deals with, i.e., the theory of knowledge and information, is extremely important. This type of research proceeds from detail to general. The generalization is not a theory in itself at all, and the presented reasoning is not intended to present a finite or internally justified theory, but it can be a contribution to the reconstruction of thinking about the mentioned area. In this way, it is also subject to the necessary verification.

Taking these assumptions into consideration, a slightly different than usual structure of the paper has been introduced. The biggest part of it is the chapter that entitled Results of the Theorizing. The conclusions regarding the ontological foundations of the discursive space are in the first part of this chapter. The adoption of these conclusions, however, does not end our reasoning but, on the contrary, it starts a new stage. A model of knowledge circulation in the world becomes possible to propose by expanding and generalizing our understanding of the ontology of the discursive space. The second part of the chapter contains a description of this idea. The third and fourth part are devoted to the consequences of adopting this model for the interpretation of the existence of information.

\section{The Initial Theoretical Context}

The world of facts appears as a reference to the concept of Ludwig Wittgenstein presented in his Tractatus logico-philosophicus [9], continued by D.M. Armstrong [10]. Armstrong also provides the concept of supervenience as a specific relationship between two entities, which has been chosen to describe the type of dependence that connects the world of facts and the discursive space. This kind of assumption paves the way for further conclusions that concern a key area in which language, understood as a tool for acquiring knowledge, comes into contact with the world.

Wittgenstein, in Tractatus logico-philosophicus, determined the relation of language and the world in a very decisive way, which can be explained by quoting Wittgenstein's two basic pairs of statements. The first pair of statements is as follows:

"3 A logical picture of facts is a thought"

and

"3.01 The totality of true thoughts is a picture of the world" [9] (p. 12).

The second one is:

"4 A thought is a proposition with a sense."

and

"4.001 The totality of propositions is language" [9] (p. 22).

The logical construction of Wittgenstein's idea is therefore simplified in the following: world, facts, thoughts, propositions, and language create the tight construction of ontological relations of the mutual identifications. This issue is extensively analyzed by McGinn [11] (p. 134) passim. These relations are not easy to explain, and all that McGinn can say in general is that "the essence of language is held to be a reflection of the essence that reality has prior to, and independently of, the construction of a language that describes it" and that "Wittgenstein's attitude towards this conception of the relation between our language and the reality it represents is problematic" [11] (p. 135). However, from the point of view of this text, it is essential to formulate the dependence of language and the world as a possibility, which makes it justified to omit the rich description of logical dependencies connecting sentences and the world presented by Wittgenstein. In Philosophical Investigations, he proposed a 
modified nature of language and the relations between language and the world that was even more complicated [12].

The world which is the subject of description by Wittgenstein is also vague and complex. Wittgenstein states:

"1.1 The world is the totality of facts, not of things." [9] (p. 5)

and

" 2 What is the case- $-\mathrm{a}$ fact-is the existence of states of affairs.

2.01 A state of affairs (a state of things) is a combination of objects (things)." [9] (p. 5)

This kind of statement is also essential for this paper. According to this view, the world is a combination of objects (things) that are the facts. The word "combination" introduces the necessity of mutual relationships between objects. Understanding these relationships as complex seems obvious. Armstrong clarifies this view: "The general structure of states of affairs will be argued to be this. A state of affairs exists if and only if a particular (at a later point to be dubbed a thin particular) has a property or, instead, a relationship holds between two or more particulars. Each state of affairs, and each constituent of each state of affairs, meaning by their constituents the particulars, properties, relations and, in the case of higher-order states of affairs, lower-order states of affairs, is a contingent existent. The properties and the relations are universals, not particulars. The relations are all external relations." [10] (p. 1). In this way, a specific world is a moving and variable convolution of certain elements (Armstrong's particulars), which, however, appear as significant only as an internally connected whole. This connection, of course, can be seen as a certain structure, as a certain order. The temptation to define this order is obvious, and it is hardly surprising that Wittgenstein tried to do it.

In this paper, there is no need to penetrate deeply enough to propose a fundamental description of the existence of the world. The starting point here is a much weaker assumption that language as a discourse reflects the world, but that does not necessarily lead to the use of such categories as truth or falsehood. This means that the possibility of resolving the problem of the existence of the world and its phenomena is also ultimately removed. It is only known that this world exists in some way and its elements, whatever they are, are observable and definable; here, it was assumed that this possibility is realized as a set of the constructions of knowledge built by means of language (discourse). In this way, the necessity of an arbitrary order managing the relation of discourse and the world (in particular, the logical order), which was the subject of Wittgenstein's extensive effort in Tractatus, is also removed. The relationship between language (discourse) and the world can be defined as supervenience in the meaning given by Armstrong: "We shall say that entity $Q$ supervenes upon entity $P$ if and only if it is impossible that $\mathrm{P}$ should exist and $\mathrm{Q}$ not exist, where $\mathrm{P}$ is possible. [ . . ] For our purposes here, it is convenient not to restrict the scope of our definition in any way. Hence the use of the term 'entity'" [10] (p. 11). This definition is very general and does not limit the objects to which it can be used but only indicates their relationship.

Relationality is also the most important premise of the reasoning presented here. Armstrong also sees relativity as a fundamental feature of the world, and what is more, believes that relativity on this level is ordered. The world is also subject to some kind of order, because the relations that create it are external, universal, or contingent. This reference to the Luhmann nomenclature [13] will be developed further. In the proposed concept of discursive space [1,14], relations combine discourse with the world of facts, but at the same time both the world of facts and the discursive space have a complex character, i.e., they are connected internally, which results in the necessity of a suitably advanced model, which is provided by the dynamic space mentioned above.

The discursive space has been described in the following way: "[it] is the epistemological construction i.e. the discursive space (DS) which is the method of the description of the massive and ubiquitous phenomena like the internet chosen as an example. This method could be also treated as the model of knowledge about the chosen phenomenon. This knowledge is understood from 
the point of view brought by sociology and philosophy which present the so-called constructivist attitude which means that the knowledge is treated by them as a social, temporary and spatially local creation. [... ] Two essential ingredients appear as the base of DS: complexity as a generic model and discourse as its direct substance." [1]. The discursive space should be treated as a convolution of partial discourses concerning a selected part of the world of facts. Because it relies on the idea of complexity, it is possible to visualize it by the parallel coordinates as a dynamical space with the arbitrarily chosen dimensions, which are built through the qualitative analysis of the discourse. This is also the place for further development of the idea of the discursive space and a cause of controversy, which has been partially resolved by the example of the existing application of the formal idea of the dynamical space in the sociology [7].

Thanks to the analysis performed by Foucault and others, discourse as a knowledge phenomenon is widely justified. Foucault also performed an extensive analysis of the relations between language (discourse) and the world [6] as the fundamental description of the history and the essence of the human knowledge and science. The reasoning presented here is not intended to raise ontological disputes but to pragmatically describe the dynamic of the knowledge. The starting point of this effort was the intention to describe such phenomena like Internet, digital transformation, and so on, which seemed to be important, pervasive, and ubiquitous, and which are under the careful consideration of such pragmatic approaches like management. However, issues of a similar scale, complexity and level of abstraction required improvement of the idea of management, which led to the construction of the theory of advanced humanistic management [15]. Thanks to epistemological self-reflection, it can serve as a universal research platform.

The discourse defined by Foucault, however, appears much later than the concept of discourse invented by Augustus de Morgan and developed and described by George Boole. In particular, Boole proposed the idea of the universe of discourse, which, according to current definitions, is complete from the point of view of the process of solving a problem belonging to this universe. To confirm this belief, the following words of Boole are usually quoted: "The office of any name or descriptive term employed under the limitations supposed is not to raise in the mind the conception of all the beings or objects to which that name or description is applicable, but only of those which exist within the supposed universe of discourse." [16] (p. 42). On the one hand, this construction is an analogue of the isolated system, and on the other it draws inspiration from the idea of mathematizing the language process, whose most-known creators are Leibniz and Descartes. The idea of mathematization, which was an important context of thinking about knowledge, and created the circumstances in which digital technology was born, was described by Maciag [17]. Boole's structure does not ultimately include the social or subjective foundations of creating knowledge by man, or resulting phenomena such as the discourse defined by Foucault. However, it is subject to the processes of formalization, which is a very serious advantage in the context of a quantitative approach upon which the idea of the discursive space is also based.

The quantitative approach in language research is otherwise very extensive. It differs fundamentally from the approach used in the case of discursive space, being in a sense complementary to it. A good example of this is intensively developing text mining, which can be considered part of the more comprehensive field of data mining. This is confirmed in much literature devoted to this technology. Although the idea of text mining is not new, it has been favored by the technical progress in the field of hardware and software, which allowed one access to various types of data, for example, provided by various web platforms, including social networking sites [18] (p. 1). The origins of text mining can be found in the 1950s and 1960s in the field of information retrieval, because document indexing is similar to the document classification used in text mining. By the 1980s, AI technology was already being used for this purpose [19] (p. 13). Aggarwal \& Zhai write that "research in information retrieval has traditionally focused more on facilitating information access [ ... ] rather than analyzing information to discover patterns, which is the primary goal of text mining" [18] (p. 2). 
Text mining, for the most part, is based on a linguistic approach that can be described as bottom-up, i.e., it specializes in the study of basic linguistic structures. Wiedeman [20] is an example of an approach that also uses sociological inspirations, but he remains at the level of basic text structures, though understood more broadly than linguistically. He also reminds us that Michel Pêcheux created automatic discourse analysis in the 1960s [20] (p. 45), [21]. This concept of discourse actualizes the social context and enables a qualitative approach; however, Wiedemann sees the discourse primarily from the perspective of a sociological method named Qualitative Data Analysis (QDA): "QDA methods provide systematization for the process of structuring information by identifying and collecting relevant textual fragments and assigning them to newly created or predefined semantic concepts in a specific field of knowledge" [20] (p. 2). His approach also refers primarily to the level of direct text and not abstract higher structures. The definition of QDA he delivered corresponds well with the definition of text mining by Heyer: "computer based methods for a semantic analysis of text that help to automatically, or semi-automatically, structure text, particularly very large amounts of text" [20] (p. 2).

\section{Results of the Theorizing}

This section is not based on empirical research but on speculation. The ideas presented here are not in the nature of findings in a sense of discoveries but, rather, are the result of reasoning and, in accordance with Popper's presented guidelines, try to present a new idea. For this reason, following free thought, this reasoning does not feel limited. It is neither exhaustive nor finite. In light of this, the following part discusses conclusions that are a generalization and development of initial assumptions regarding the ontological status of discursive space based on the idea of supervenience. These conclusions concern the model of knowledge circulation in the world and the way the phenomenon of information exists.

\subsection{Initial Remarks: Supervenience}

The first step in this reasoning consists of drawing conclusions from the construct's proposal, which is the discursive space. As it was assumed, it exists in the relationship of supervenience with the world of facts, which means that the shape of this relationship does not in any way preexist but is born as a result of the properties of the interacting parties (Figure 1). The only thing we know about the relationship of supervenience in the case of discursive space is that every element of the world of facts must have a reflection in the discursive space. Of course, the dynamics of achieving such a state is in no way determined. Adding the time factor to the definition of Armstrong, which he allows, emphasizing the lack of restrictions on the scope of its definition, removes the objection concerning the incompleteness of the discursive space. In fact, the discursive space tends to be a state that implements the principle of supervenience, or knowledge tends to embrace the whole world of facts. This assumption is non-controversial.

The next conclusion concerns the nature of the discursive space. The world of facts is complex-this assumption is also uncontroversial-so the complex nature of discursive space is necessarily complex too, which results from the relation of supervenience. The complexity of discursive space subsequently allows for emergent phenomena. Such phenomena are, e.g., the internet or digital transformations that exist as linguistic entities. However, they are also expressions of knowledge, which result from the idea of discourse. They can therefore also be called epistemological constructions, if we assume that knowledge is the result of the cognitive process. This last observation seems to transfer the problem to a level strongly associated with the subject in the meaning of man. However, such a relationship is not necessary; Burgin wrote: "cognitive systems, e.g., intelligent agents or cognitive actors, store and employ a variety of epistemic structures in different forms and shapes" [22] (p. 177). A similar possibility in the process of dealing with knowledge I assumed independently in [23] as an element of the so-called pragmatic management concept. 


\section{Emergent phenomena eg. digital transformation}

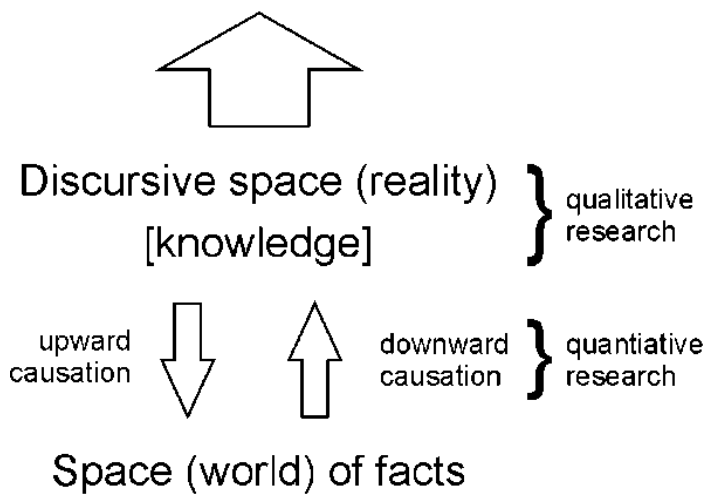

Figure 1. Ontological relations between discursive space, space of facts, and digital transformation.

Discourse (discourses) may be presented as a trajectory (trajectories) in discursive space, the dimensions of which define the existing knowledge associated with them. This is described in more detail in [1]. In the space described there, 20 dimensions create a discursive space for a discursive entity like the Internet, which represents knowledge about it. The position of the Internet in these dimensions changes over time.

Such reasoning leads to a serious problem concerning the best way to realize the relationship of supervenience, which is known to have certain dynamics and to develop over time. The presented concept assumes that it has a reciprocal character, which results from the specifics of discourse, which on the one hand is shaped by the world of facts but on the other affects this world. Foucault draws attention to the various effects of the discourse in the social world [4,5], which can be summarized as power relations, but this possibility also opens other modes of the influence of the discourse on the world of facts, but these are not necessarily clear. This situation appears as a separate case requiring exploration and study. The mentioned problem is in the nature of these relations. In other words, how practical is the mutual influence realized in a situation in which the ontological status of the world of facts and language (discourse) is different? This question is not usually asked, since we assume silently that this is the nature of the language used to describe the world.

\subsection{Further Findings: Towards the Unification of the World}

This section describes the wider context of the functioning of the idea of discursive space and the further consequences of such an approach. The presented reasoning is an extrapolation of assumptions and conclusions regarding the discursive space.

We are dealing with the situation presented in Figure 2 according to the presented idea of discursive space. The combination of a qualitative and quantitative approach in the case of the construction of the idea of the discursive space as a dynamical space makes it possible to present the space using the parallel coordinate system that was described above. However, there is no reason to treat the discursive space as unique or the only system devoted to acquiring knowledge. Let us treat the discursive space as any similar system aimed at this goal. 


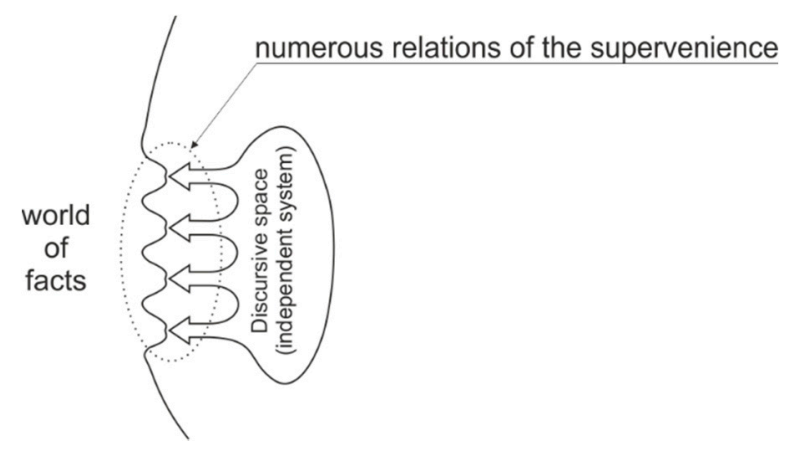

Figure 2. The world of facts and the discursive space.

The situation presented in Figure 2 could be treated as the well-known schema of interaction between the separated system and its environment, which is the canonical situation in the system theory. The main conceptual achievement of the General System Theory (GST) by Bertalanffy and others is the representation of the world as separated but interconnected entities. Skyttner, who collects the efforts of many researchers, presents a list of hallmarks of the theory of systems. Among them, on one hand, there is holism, on the other differentiation and even the hierarchy of related and interdependent objects and their attributes [24] (p. 53). Other attributes mentioned by him are goal seeking, the transformation process, inputs and outputs presence, entropy, regulation, equifinality, and multifinality.

The situation becomes more complicated, however, as the scope of the system approach increases. In the area of cybernetics, for example, this is about moving to a level of the second order of the cybernetics; the so-called cybernetics of cybernetics. $[25,26]$. Umpleby called this move "a fundamental revolution in science" [27] and perceives it as a contribution and an introduction to the wider project entitled second-order science [28]. Skyttner sees a breakthrough in the rejection of the deterministic approach, which takes place at the beginning of the twentieth century with the appearance and development of quantum theory, which forces science to fundamentally reorient the relationship of the observer to the world [24] (p. 23) passim. Examples of the most recent and very advanced analysis of this problem appear as issues of the presence and status of an observer in the context of the artificial intelligence $[29,30]$. It is worth noting that the issue of the scale of the complex systems is also a problem in itself (e.g., [31]).

An important contribution to understanding this situation is made by Mark Burgin. He introduces the observer-oriented approach to knowledge, which means "that an observer (user or knower) characterizes and utilizes some epistemic structures as knowledge" [22] (p. 80). Introducing the idea of an observer can solve the problem of the truthfulness of knowledge, which becomes irrelevant. Criteria of knowledge ("the existential characteristics of knowledge") could have the temporal and subjective character. The striving to acquire "objective" knowledge, Burgin reminds us, results from the condition formulated by Plato in his dialogue entitled Theaetetus as a part of the definition of knowledge: Dóksa alethés metá logú in English translation by Waterfield: "true belief accompanied by a rational account" [32] (p. 115), usually shortened to justified true belief [33]. However, various objections, among them the famous Gettier problem [34], undermine the possibility of such knowledge.

As one can see, we deal with the two directions of the problematization of the second-order approach and they are not identical: in the first case, we deal with the cognitive process of extension of the system under investigation by introducing the higher level of its self-referentiality. In the second, this self-referentiality concretizes itself to the existence of an observer who is the subject (agent) of this self-referentiality. Both these directions, however, mark a truly fundamental movement against the isolation of the system, and thus towards all the possible relations that it creates. Such a transition to the second-order analysis level in this paper leads to the conclusion that the situation presented in Figure 2 is simplified, because without a doubt the discursive space, which has been presented as an independent system, is actually the part of the world of facts (world of affairs), since the nature of 
facts (affairs) is unspecified. Wittgenstein uses the notion of object or thing; more general is the notion used by Armstrong, who speaks about the "particular" and underlines its relational character. The discursive space fulfills these demands, since it contains interconnected discourses, and each of them is a complex system of notions, cognitive constructions, and so. The definition delivered by Armstrong is intended to be as general as possible in order to gather as wide a spectrum of entities as possible. If so, we deal with the situation that the system that is established to acquire knowledge (i.e., the discursive space but any other such a system, too) is the part of the world of facts or, in other words, the whole. This situation is presented in Figure 3.

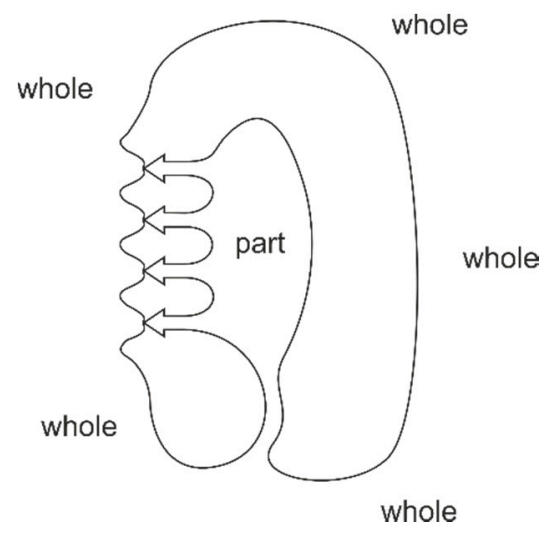

Figure 3. The real situation of the existence of the discursive space.

The next step of our reasoning can be justified by the definition of the observer presented by Burgin: "Usually, an observer is treated as a physical system that in the same way, i.e., physically, interacts with the observed object. Very often, an observer is interpreted as a human being. However, here we use a broader perspective, allowing an abstract system also to be an observer because in our case the observed object is knowledge, i.e., it is an abstract system itself. In addition, it is necessary to understand that interaction between abstract systems involves representations of these systems and the performing system, which perform interaction and is usually physical" [22] (p. 83). From this definition, knowledge systems are numerous, can be interrelated, and can exist for very different observers.

In our case, the system of knowledge is the discursive space that is the convolution of discourses. An observer is a human being as a social being, in accordance with the idea of discourse immersed in a certain spatial and temporal reality. This reality affects the formation of discourses and the knowledge they articulate in a variety of ways. Because discourse is a linguistic creation, it is undoubtedly at the disposal of man, but, on the other hand, both language and discourse implement the idea of abstract systems in the meaning of Burgin: abstract observer [22] (p. 83). According to Burgin, on the one hand, the discourse has an internal character. It is knowledge, and thus fulfills the assumptions of the abstract internal observer; on the other hand, it has an external character, because it exists in opposition to the world of facts. Burgin devotes very little space to the description of differences between the internal and external observers. In the case of the situation described in this paper, the game between what is internal and external has a key importance.

Combining the idea of the abstract observer by Burgin with the Armstrong construction of the existence of the world (state of affairs as the continuation of the world of facts by Wittgenstein), we can assume that the part (the system, e.g., the discursive space) realizes the self-observation of the (certain) whole in order to achieve the knowledge about it in a particular goal. The scope of the whole could be various and primarily means everything (the world) but could also mean the specific part of the world that is functioning as a whole for its parts. The combination of numerous and related knowledge systems within the chosen whole is possible thanks to the ontological assumption that enables the extension and unification of the world of facts. A similar holistic approach appears in the cited definition of Burgin, although it is implemented as a list of possible and different ontologically variants: 
real external observer, abstract external observer, and internal observer. Ontological unification also opens up the possibility of the existence of an unlimited number of knowledge systems. They can acquire knowledge from various areas of the world of facts, including other knowledge systems, since every knowledge system must be part of the world of facts. Such a situation allows for the existence of a mutual knowledge structure of potentially infinite complexity. A simplified scheme of such a structure could look like the image presented in Figure 4.

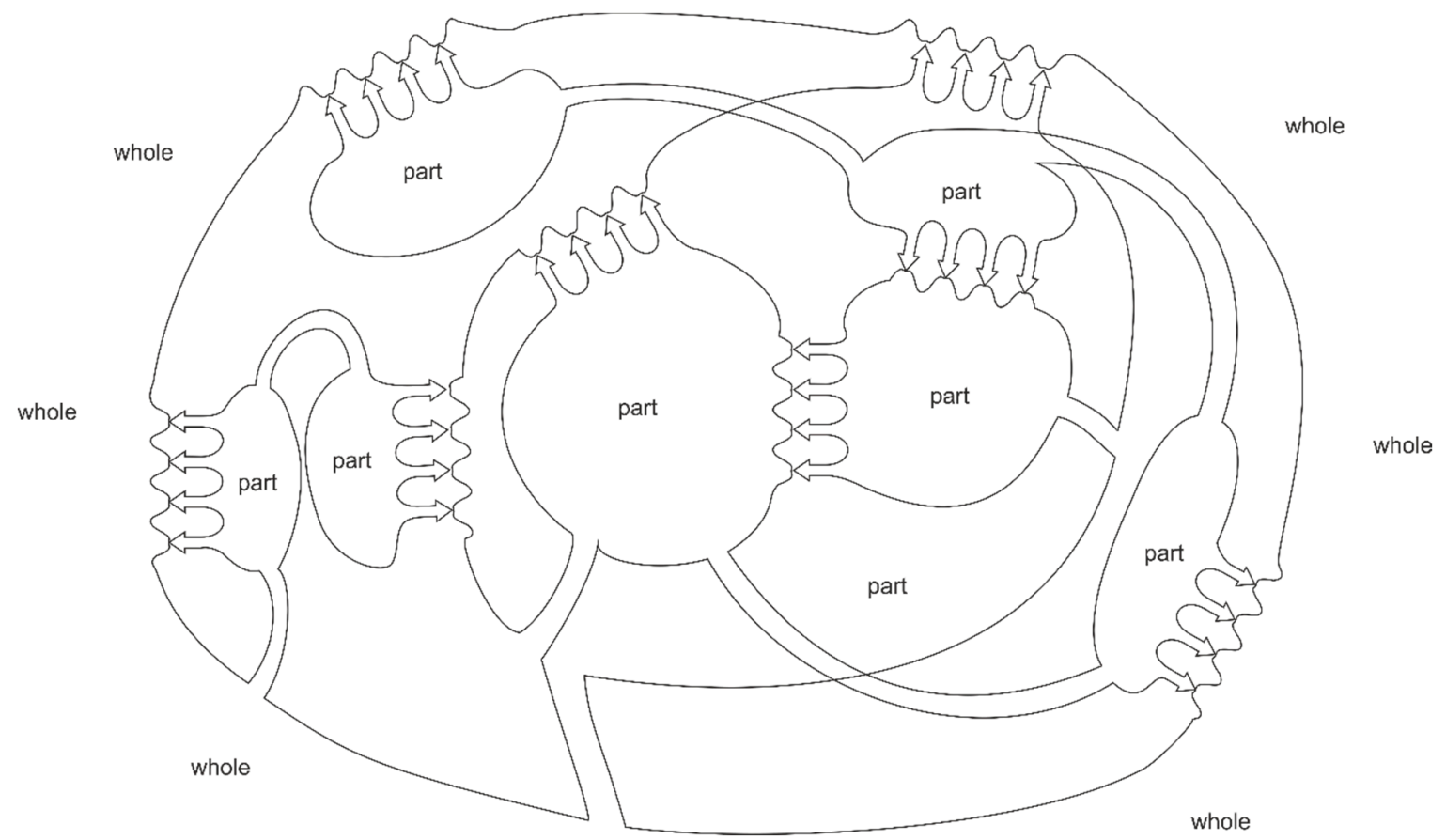

Figure 4. Simplified example of the structure of knowledge acquisition.

The suggestion of a similarly unlimited approach in the perception of systems is presented by Luhmann. Although the subject of his analysis is social systems, he treats them as representative variants of the systems as such: "general systems theory does not fix the essential features to be found in all systems. Instead, it is formulated in the language of problems and their solutions and at the same time makes clear that there can be different, functionally equivalent solutions for specific problems" [13] (p. 15). This statement also means that there is a level of abstraction in which one descriptive system structure is allowed; however, it cannot be unified, because it needs local and different descriptions of problems articulated in a specific way. That means that this level of abstraction cannot be gathered by the unified and coherent knowledge if this knowledge is articulated in language-such a knowledge is considered here as a consistent and homogenous system. From our point of view, this is obvious, because knowledge, as a rule, is not consistent but broken into an undetermined but potentially large number of knowledge systems.

The mechanism that replaces, e.g., knowledge understood as onefold system as a unifying platform for system analysis is, according to Luhmann, a mechanism of double contingency: "Something is contingent insofar as it is neither necessary nor impossible; it is just what it is (or was or will be), though it could also be otherwise. This concept thus describes something given (something experienced, expected, remembered, fantasized) in the light of its possibly being otherwise; it describes objects within the horizon of possible variations. It presupposes the world as it is given, yet it does not describe the possible in general, but what is otherwise possible from the viewpoint of reality" [13] (p. 106). The construction connecting the fact of the real existence of something and the possibility of "being otherwise" in the same moment is the key to this reasoning. In other words, something must happen even if something else is possible. This means selection. In our case everything is ontologically identical, and we deal with facts or states of affairs, so the mutual influence 
takes the form of the change that occurs in the two sides that meet (shown as the deformation on Figures 2-4). The change introduces differentiation to the previous, known state. In the case of social systems according to Luhmann, "[the double contingency] enables the differentiation of a particular world dimension for socially distinct meaning perspectives (the social dimension) and it enables the differentiation of particular action systems, namely, social systems" [13] (p. 106). Differentiation takes place at the same time on both sides, comprising a certain given social system and its surroundings that are important for this system. Differentiation has been also used for the explanation of the most difficult part of the information: the reference and significance. The idea proposed by Deacon tries to cross the border between the separated worlds and offers a way of the formalizing the "aboutness" [35].

\subsection{Possible Proposals: Information}

This part has the most uncertain nature, partially because of its speculative character and partially because of its preliminary state. Because of the extraordinary scope of existing reflection, it seems irresponsible to take such a topic as information. I must underline again that the purpose of this paper is not general information theory. Such bold and labor-intensive attempts have already been made, e.g., in references [36-38]. However, as it has been written, it is necessary to draw conclusions from reasoning about the dynamics and role of discursive space.

According to the presented analysis, the discursive space can initially be understood as a separate being, which is the realization of certain knowledge. However, developing this theory based on the concepts of Wittgenstein and Armstrong leads to the simple conclusion that, in fact, we are dealing with one world. If so, the discursive space is simply a creation within this world that aims to gather knowledge about it. Using the assumption presented directly by Burgin, knowledge is gathered in many places and for many reasons. Of course, this assumption is present in the literature devoted to information, e.g., in references [36,39,40]. Because of the existence of a single world of facts, the place of gathering knowledge must always carry out the model shown in the case of discursive space. Instead of the concept of "place", according to the prevailing principle of description in the area of the theory of knowledge and information, the term "system" is used here. So, knowledge systems are parts of the world of facts. If so, we will have to deal with two further consequences: first, these systems create a structure within the world of facts and, secondly, differentiation can be the answer to the question of how they exist.

The introduction of the differentiation notion in the context of knowledge requires the presence of the reflection in the information phenomenon. As a starting point, take the remaining most famous and the most frequently cited definition of the information by Bateson, here quoted in a shortened form that nevertheless introduces the most general and basic interpretation (a comprehensive review of such definitions is provided by Burgin [37]). The whole passage is as follows: "Information, in the technical sense, is that which excludes certain alternatives. The machine with a governor does not elect the steady state; it prevents itself from staying in any alternative state; and in all such cybernetic systems, corrective action is brought about by difference. In the jargon of the engineers, the system is "error activated." The difference between some present state and some "preferred" state activates the corrective response. The technical term "information" may be succinctly de-fined as any difference which makes a difference in some later event. This definition is fundamental for all analysis of cybernetic systems and organization" [41] (p. 386).

As one can see, the "de-finition" by Bateson refers to the technical cybernetic systems and introduces three important elements: one deals with one system, which remains in a certain state, which in turn changes over the time. There is the past state, which is in some way different than expected, and the future state, which is the consequence of the past state. The future state is difference in the system caused by past difference and must happen after. One can say that we deal with the reconciliation between the past and future, which has the technical term the feed-forward and is not very original. The originality comes with the idea of difference, whose ontological status is not obvious. The papers of Derrida [42] present the most comprehensive analysis of difference; Derrida coined the 
complex term la différance, which was the combination of difference and deferring. Both the inclusion of a time variable into the process of revealing difference and the field of problem analysis, which is the reality of meanings and text, mean the reference to Derrida may be justified and fruitful in our context; however, the present concern is the level of abstraction used by Bateson. This level has a paradoxical character: in the context of the reflection it is physical, but with the introduction of the term of difference it becomes also ontological, i.e., metaphysical (what could be understand as speculative). It is worth adding that the definition of information appears as a digression in the context of the main problem of Bateson, which is the development of bilateral symmetry of animals and plants. This context is, on one hand, clear in its reality and, on the other, it shows the generality of the notion of the information, the generality that could be understood as a high level of abstraction.

A similar approach appears in Luhmann theory about the double contingency, which is not a surprise, since Luhmann makes the communication the basis of the social processes: the communication that he understands as transmitting the information [13] (p. 139) passim. At the same time, Luhmann criticizes the metaphor of transmission as a suggestion of the transfer of something identical for both sides, and even as something substantial, and points out that information is only a selection: "communication constitutes what it chooses, by virtue of that choice, as a selection, namely, as information" [13] (p. 140). Different contexts (horizons) of this selection cause it to be perceived differently. The concept of selection by Luhmann is based on the theory of Shannon and Weaver.

Differentiation and selection are terms that are complementary in the temporal sense; selection takes place thanks to the existence of differentiation. There is no selection without diversity. Information in this light is at the same time a diversification and selection, because one does not exist without the other (and this conclusion belongs to an uncomplicated ontological reflection). Moreover, both terms refer to a certain pre-existing reality; something is subject to differentiation as something is the subject of selection. The former means another, although this otherness may result from both the time shift (Bateson) and the existence of a specific social world, which is the context of the social system (Luhmann). Such an alternative is a signal that the question of diversity should not be understood too simply, and, in particular, it should not be simplified ontologically.

Trying to explain the mutual location of these closely-situated concepts (difference and selection), it is worth noting a proposal of a completely different understanding of information by Burgin. In the Theory of Information, he presents a complete ontological description of information, which consists of seven principles. The Ontological Principle O2 (the General Transformation Principle) is of particular importance: "In a broad sense, information for a system $\mathrm{R}$ is a capacity to cause changes in the system $\mathrm{R}^{\prime \prime}$ [37] (p. 99). In the next five principles, Burgin deals mainly with the presence and functions of the factor that he calls "the carrier", fulfilling the function of the information vehicle. In the first principle (OP1), Burgin distinguishes the information "in general" from information "for a system R" [37] (p. 92); this distinction can be considered void in the light of his subsequent book The Theory of Knowledge [22]. The fundamental difference that separates Burgin from Bateson and Luhmann in the approach to information is the omission of the presence of the precendent area, which so significantly appears in Bateson and Luhmann, and the "shortening" of the existential process in which information becomes.

For Hofkirchner, the basis for the existence of information as a system is self-organization, and what is more, it emphasizes the network nature of this phenomenon, placing it in the general context of the physical world: "We can conclude: information is involved in self-organisation. Every system acts and reacts in a network of systems, elements and networks, and is exposed to influences mediated by matter and/or energy relations" [36] (p. 170). It also treats information as a result of a special type of differentiation: information "is generated if self-organising systems relate to some external perturbation by the spontaneous build-up of order they execute when exposed to this perturbation." [36] (p. 172). The term "perturbation" comes from Maturana and Varela and means "the influence from outside self-organisation" [36] ibidem. This reasoning assumes that the world is a structure of identifiable systems. Information that is the result of an unexpected cause-and-effect process within the system 
enables their formation and development in a self-organizing way. Precise analysis of the processes that accomplish this leads to the idea of universe of information, which is possible to describe on one side using the typology of the information, i.e., the specific abilities of the information and on the other by the different kinds of its functionality giving a clear array of possibilities of the combinations [36] (p. 197). It is only in the light of this type of conclusion that such phenomena as knowledge and wisdom are interpreted.

Hofkirchner considers knowledge as a variety of the capability of the reflexivity, "which is a feature of human thinking only" [36] (p. 205). In this paper, knowledge is regarded as "a feature" of any cognitive system. This assumption makes knowledge the general notion for the analysis. This completely reverses the point of view compared to the fundamental and definitely broader and more detailed reasoning by Hofkirchner and could be regarded as potentially fruitful. The intention of this change, which inevitable in the light of the analysis of the discursive space, is to create the more general base for the reasoning, while knowledge becomes a phenomenon offering such a possibility. Information in this situation becomes a derivative of knowledge processes and only has a supportive character that realizes different features such as those described by Hofkirchner. Relations between knowledge and information should then be reworked substantially, which is the task for future work. In the light of such approach, one can speak about the universe of knowledge that is not understood through a typological and functional description but through the ontological wholiness it possibly creates.

\subsection{Conclusions of the Possible Proposals}

From the above-presented reasoning, the approach presented by Bateson and Luhmann and partly by Burgin is fundamental. It involves perceiving information as a manifestation of a larger whole, not an individual, which is accompanied by the exclusion of substantiality of the information. This manifestation occurs as disorders (differences). Foucault similarly describes the trait of the existence of discourse, which is for him the way knowledge exists. He calls this feature "exteriority" [4], which "calls for the abandonment of the immanence of discourse, which reveals itself as the action, but not as the substance" [1]. Such a point of view is also imprinted in the schema presented in Figure 4. Knowledge systems emerge as the sovereign elements of larger entities, maintaining the principle of double contingency. Formation of these knowledge systems runs in time. Thanks to this, the needs of the system as a whole regarding knowledge are realized. In this context, the concept of knowledge must trigger the existing concept of information.

The only places in the diagram in which we can deal with the flow of knowledge are the points indicated in Figure 5 that must also indicate the flow of the information. The information described in this way may have a slightly different character than previously thought, although it has precedents in science. Its nature is revealed only in a larger whole, for which a maximum increase in the perspective of the research look is needed, which can be described as an upper level or second-order approach. This view is represented by Bateson and Luhmann. In the case of Burgin, the horizon of the ontological definition of information reaches only the limits of the factor called "carrier" (the idea of the existential triad of the world demands separate analysis in this context). Hofkirchner assumes information as the main phenomenon and treats knowledge as a secondary phenomenon necessarily connected with human capabilities only. Such an approach is completely different than the one chosen here. 


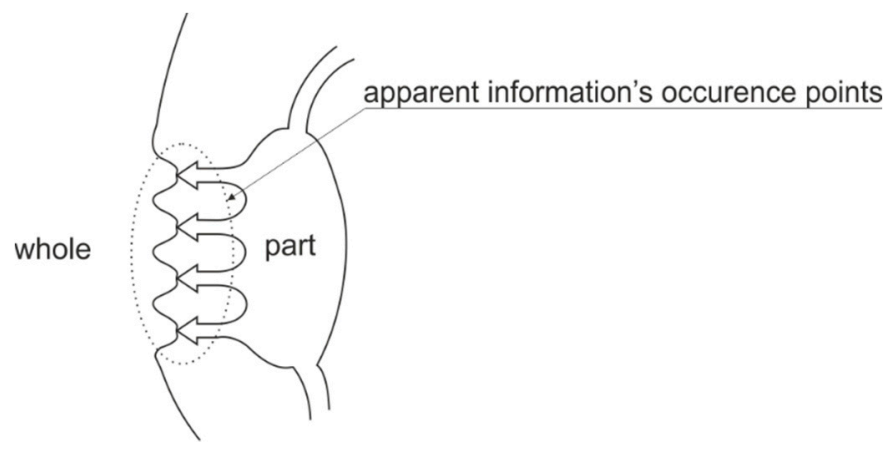

Figure 5. Apparent information localization in the knowledge circulating process.

Information perceived from the perspective of the whole world according to the scheme shown in Figure 5 appears to be an interface, a gate, a synapse that is created to allow the flow of knowledge. From the point of view of the whole, the information enables synchronization of all processes of flowing knowledge that are constantly developing and complicating, thus maintaining the circulation of it in the world. In this sense, information can be seen in each of the places in which it reveals itself as a kind of interaction, and from the perspective of the world as a certain interacting whole. This is basically the Hofkirchner stance, which analyzes the ways the information occurs in detail [36] with the proviso that the information is only the tool for realizing the knowledge system, which should be considered as a whole. Because information reveals itself indirectly and as an impact, the subject of impact determines its phenomenal shape. If such a way of the existence of information is assumed, it would be a functional whole that is structured internally, develops in time, and is the source of numerous interactions.

\section{Discussion on the Discourse Notion}

The concept of discourse, which is of key importance, needs to be discussed in more detail. The most important problem of discourse from the point of view of the presented reasoning is its ontological status, which is out of focus. The two main interpretive traditions of discourse (the idea of Boole and the idea of Foucault) followed different paths, although they had a common starting point. In the first case, the abstract approach prevails, in the second, the real social context. Discourse as a cognitive construction (and at the same time a descriptive category) reflects the fundamental problem of describing the world by trying to reconcile two realities: the description and the world, which are combined in a relationship that is extremely difficult to grasp. In literature devoted to discourse, one can find evidence for the realization of this relationship as a fundamental feature of discourse: firstly, defining discourse as articulation/retention of knowledge; secondly, because this knowledge has a specific, local (temporal and spatial) character. These two factors are understood in a qualitative way, but it does not exclude their more formal interpretation.

Van Dijk, who is one of the most important researchers in this phenomenon in the 20th century, emphasizes the immersion of discourse in a social context: "We need to account for the fact that discourse as social action is being engaged in within a framework of understanding, communication and interaction which is, in turn, part of broader sociocultural structures and processes" [43] (p. 21). Fairclough, however, emphasizes the existence of a specific order of discourse, which social practice enriches for a certain existence which is spontaneous: "I see discourse analysis as 'oscillating' between a focus on specific texts and a focus on what I call the 'order of discourse', the relatively durable social structuring of language which is itself one element of the relatively durable structuring and networking of social practices" [44] (p. 3).

Fixing the discourse in the reality of social practice, i.e., the perception of discourse as a real social being is justified by its direct participation in the circulation of knowledge. This is strictly admitted by Hyland \& Paltridge: "discourse is socially constitutive as well as socially shaped: it constitutes situations, objects of knowledge and the social identities of and relationships between people and 
groups of people" [45] (p. 39), and Jørgensen \& Phillips: "the struggle between different knowledge claims could be understood and empirically explored as a struggle between different discourses which represent different ways of understanding aspects of the world and construct different identities for speakers" [46] (p. 2). The relationship between discourse and knowledge can also be understood as an indirect dependence that is still very important: "discourse theory often revolves around the nexus of power, knowledge and subjectivity" [47] (p. 6), "the role of context in the production and understanding of discourse is fundamental. Since knowledge is part of the context, each level of discourse structure depends on the knowledge of the participants" [48] (p. 592).

The concept of discourse as a social phenomenon has been introduced in 1952 by Zelig Harris and since then has developed into many different approaches. Two basic directions are indicated by Paltridge: "range from textually-oriented views of discourse analysis which concentrate mostly on language features of texts, to more socially-oriented views of discourse analysis which consider what text is doing in the social and cultural setting in which it occurs" [49] (p. 1). This division also appears in the reflection of knowledge in the context of discourse. On the one hand, it concerns, for example, a particular problem (organizational knowledge); on the other, it allows a philosophical approach of great generality $[5,6,50]$. Michel Foucault is still the author, whose thought is still the most important inspiration for most contemporary discourse researchers [44] (p. 2), [46] (p. 13), while presenting such a far-reaching description of his ontological status [4].

The concept of discourse, however, appears much earlier and in another research tradition as a component of the phrase "the universe of discourse". The Cambridge Dictionary of Philosophy states "the concept of universe of discourse is due to De Morgan in 1846, but the expression was coined by Boole eight years later". This expression describes the rather formal and strict entity: "universe of discourse, the usually limited class of individuals under discussion, whose existence is presupposed by the discussants, and which in some sense constitutes the ultimate subject matter of the discussion. Once the universe of a discourse has been established, expressions such as 'every object' and 'some object' refer respectively to every object or to some object in the universe of discourse" [51] (p. 941). A Companion to Philosophical Logic underlines the arbitrary and restricted character of the concept of the "universe of discourse" in an even more limited way, which is "still generally used, as a way of targeting statements to a class of objects under discussion, rather than the entire universe" [52] (p. 42). Similarly, The Computer Science and Communications Dictionary states: "in a particular context, all of the entities or elements that (a) are of interest and (b) may include (i) many entity worlds and (ii) entities that are not yet perceived or considered" [53].

These explanations gravitate towards a strict, formal, and theoretical kind of the description, whereas the intention of the Bool was different: "In every discourse, whether of the mind conversing with its own thoughts, or of the individual in his intercourse with others, there is an assumed or expressed limit within which the subjects of its operation are confined. The most unfettered discourse is that in which the words we use are understood in the widest possible application, and, for them, the limits of discourse are co-extensive with those of the universe itself. But more usually we confine ourselves to a less spacious field. Sometimes, in discoursing of men, we imply (without expressing the limitation) that it is of men only under certain circumstances and conditions that we speak, as of civilized men, or of men in the vigour of life, or of men under some other condition or relation. Now, whatever may be the extent of the field within which all the objects of our discourse are found, that field may properly be termed the universe of discourse. Furthermore, this universe of discourse is in the strictest sense the ultimate subject of the discourse" [16] (p. 42). The intention of embedding this concept in reality is very clear. This is partly explained by the relatively early time of its creation. This is the period just before the crucial breakthrough in the understanding of the character of the relation of the mathematics and, above all, of geometry to the real world, and in particular before the emergence of issues raised by Hilbert regarding the existence of mathematical structures (e.g., the famous Hilbert letter to Frege from 1899 [54] (p. 40)). 


\section{Conclusions}

The reasoning presented here has two structurally significant phases: in the first one, the construction of discursive space has been clarified as a construction of knowledge, the concept of which was presented in [1]; in the second, using the gathered premises, the conclusions were generalized by presenting ontological analysis of the possibility of knowledge and information existence in the light of the concept of the discursive space. The second part is an extrapolation of the particular example of the discursive space.

Summarizing the reasoning presented here, we must, therefore, return to the original descriptive structure, which is the discursive space. The way of understanding it has been greatly expanded here. The initial space that has been assumed as the environment of discursive space is language that is functioning not as a certain independent system but as the implementation of this system in the world; discourse is language realized in reality, which has the ability to gather and organize knowledge, in accordance with the theory of discourse stated by Foucault. It is this ability, it seems, which distinguishes the idea of Foucault's discourse from the idea of Boole's discourse, because the latter is only an undetermined environment of opportunities, whereas Foucault's discourse is determined in the sense that it is historical, local, and significant, i.e., it is knowledge. The sources of this intuition undoubtedly came with Wittgenstein. The way in which this kind of discourse exists describes Foucault with the help of the following four rules: reversal, discontinuity, specificity, and exteriority, and this is the existence that I tried to interpret as complex. Foucault, from the moment of his doctoral presentation in 1961 based on thesis entitled Folie et déraison. Histoire de la folie à l'âge classique [55], devotes a lot of space and time to providing evidence for the existence of discourse that he described by analyzing the specific impact of discourse on the world, which is, both social and cultural.

The key step here is to assume that discourse is also part of the world (world of facts, state of affairs), which has become possible thanks to the premises provided by Wittgenstein and Armstrong. In particular, it is about the withdrawal from thinking about discourse as a certain entity possessing a substantial character and replacing it with a relational character, which makes the discourse visible only through its influence. This property has been predicted and described by Foucault, who called it exteriority. In a similar way, Armstrong describes the world as such, drawing inspiration from Wittgenstein; the existence of the world, which he calls the state of affairs, he builds from the properties and relationships of certain indeterminate (arbitrary) particulars. Characteristic features of particulars are properties and relationships that are universal; relations are also external relations. Because language undoubtedly belongs to the world, its realizations such as discourse also belong to the world. The complex nature of discourse means that its existence must be based on relationships.

Thanks to this reasoning, we can try to construct a model of the world in which, by analogy with the idea of discourse, every flow of knowledge has dynamics similar to those that occur in the case of discourse. This is the result of the ontological unification of the world (discourse is also part of the world), which strictly means that it is a set of relations (and properties, which here are less important) of certain particulars. On the other hand, by reversing the approach, discourse can also be considered as not only specific or accidental but as one of many realizations of the set of relationships.

The ontological unification of the world and basing it on relations can lead to interesting conclusions about the circulation of knowledge. This circulation has been described using a slightly modified concept of information. The final conclusion presents a model of interrelated, equivalent knowledge systems, for which information enables mutual relations of parts within the whole world. In this model, something that Burgin calls the carrier changes its role and becomes even irrelevant, and the existence of relationships that are evident as changes on both sides becomes important. This change must take place in the entity that Armstrong called a particular, in its properties and relationships, but what is considered a particular at the moment is irrelevant to the world of affairs.

From the analysis of the mutual position of the world of facts and discursive space, which by assumption are connected by a supervenience relationship, the necessity of introducing the variable of 
time emerges, which results from the historical and local character of discourse. Actually, an infinite process to realize supervenience proceeds, which, due to the complexity of the world of facts, is impossible to achieve in the foreseeable future, and which agrees with the ordinary experience of knowledge development. On the other hand, the relational configuration does not determine such values as truthfulness or falsehood. These categories are not applicable here; relationships are not judgments about the world. Putting aside the classical knowledge requirement of truth (knowledge as justified true belief) is also the result of a long process of understanding knowledge, including scientific knowledge, and appears in papers by Foucault, among others. This process, however, is based on the observation of internal procedures for collecting knowledge by a human being as a subject and as a social being. This type of approach appears in the developing trend of the so-called constructivist. Support for such an approach also appears unexpectedly on the part of advanced digital technologies. It seems, however, that a large part of the discussion devoted to knowledge, in particular, scientific knowledge, especially in the 20th century, resulted from the need to solve the problem of its truthfulness, which from the point of view presented here is a kind of misunderstanding. This aspect certainly requires further work.

On the other hand, if discourse is a nonspecific case of the universal process of knowledge transfer, which takes place as a network of relations that leads to changes that are later sources of further functioning of the world of facts (world of affairs), it can be assumed that some features of this process are also universal. From this, it would appear that the discursive space model can be used to describe other flows of knowledge. Such an approach would present the possibility of applying the idea of dynamical space to all situations in which we deal with knowledge that can be described as trajectories of its partial components (discourses or concepts). Of course, this would mean abandoning the idea of stable and objective knowledge in favor of ad hoc processes of flow, which would result in a completely different model.

Funding: This research received no external funding.

Conflicts of Interest: The author declares no conflict of interest.

\section{References}

1. Maciag, R. The analysis of the internet development based on the complex model of the discursive space. Information 2018, 9, 7. [CrossRef]

2. Nolte, D.D. Introduction to Modern Dynamics: Chaos, Networks, Space and Time, 1st ed.; Oxford University Press: New York, NY, USA, 2015, ISBN 978-0-19-965704-9.

3. Nolte, D.D. The tangled tale of phase space. Phys. Today 2010, 63, 33-38. [CrossRef]

4. Foucault, M. The order of discourse. In Untying the Text: A Post-structuralist Reader; Young, R., Ed.; Routledge \& Kegan Paul: Boston, MA, USA, 1981; pp. 51-78.

5. Foucault, M. The Archaeology of Knowledge and the Discourse of Language; Pantheon Books: New York City, NY, USA, 1972, ISBN 978-0-394-71106-5.

6. Foucault, M. The Order of Things: An Archaeology of the Human Sciences; Routledge: London, UK, 2002, ISBN 978-0-415-26736-6.

7. Byrne, D.S.; Callaghan, G. Complexity Theory and the Social Sciences: The State of the Art; Routledge, Taylor \& Francis Group: New York, NY, USA, 2014, ISBN 978-0-415-69367-7.

8. Popper, K. The Logic of Scientific Discovery, 2nd ed.; Routledge: London, UK, 2002, ISBN 978-0-415-27844-7.

9. Wittgenstein, L. Tractatus Logico-Philosophicus, 2nd ed.; Routledge: London, UK; New York, NY, USA, 2002, ISBN 978-0415254083.

10. Armstrong, D.M. A World of States of Affairs; Cambridge University Press: Cambridge, UK, 1997, ISBN 978-0521589482.

11. McGinn, M. Elucidating the 'Tractatus': Wittgenstein's Early Philosophy of Logic and Language; Oxford University Press: Oxford, UK, 2006, ISBN 978-0-19-924444-7.

12. Wittgenstein, L. Philosophical Investigations; Blackwell: Oxford, UK, 1953. 
13. Luhmann, N. Social Systems; Stanford University Press: Redwood City, CA, USA, 1995, ISBN 978-0-8047-2625-2.

14. Maciag, R. The analysis of the internet development based on the complex model of the discursive space. Presented at the IS4SI 2017 Summit Digitalisation for a Sustainable Society, Gothenburg, Sweden, 12-16 June 2017.

15. Maciag, R. Cyber physical systems by humanistic management. Introduction. In Proceedings of the 2017 IEEE 15th International Conference on Industrial Informatics (INDIN), Emden, Germany, 24-26 July 2017; pp. 911-916.

16. Boole, G. An Investigation of the Laws of Thought: on Which Are Founded the Mathematical Theories of Logic and Probabilities; Walton and Maberly: London, UK, 1854.

17. Maciag, R. Deus ex machina: nowe media i ich projekt poznawczy; Wydawnictwo Uniwersytetu Jagiellońskiego: Kraków, Poland, 2012, ISBN 978-83-233-3375-3.

18. Aggarwal, C.C.; Zhai, C. (Eds.) Mining Text Data; Springer: Boston, MA, USA, 2012, ISBN 978-1-4614-3222-7.

19. Weiss, S.M.; Indurkhya, N.; Zhang, T. Fundamentals of Predictive Text Mining; Springer: London, UK, 2010, ISBN 978-1-84996-225-4.

20. Wiedemann, G. Text Mining for Qualitative Data Analysis in the Social Sciences; Springer Fachmedien Wiesbaden: Wiesbaden, Germany, 2016, ISBN 978-3-658-15308-3.

21. Pêcheux, M. Automatic Discourse Analysis; Hak, T., Helsloot, N., Eds.; Rodopi: Amsterdam, The Netherlands, 1995, ISBN 978-90-5183-645-5.

22. Burgin, M. Theory of Knowledge: Structures and Processes; World Scientifc Publishing Co. Pte. Ltd.: Singapore, 2015, ISBN 978-981-4522-67-0.

23. Maciag, R. W strone cywilizacji Internetu: zarzadzanie w naukach humanistycznych; Wydawnictwo Uniwersytetu Jagiellońskiego: Kraków, Poland, 2016, ISBN 978-83-233-4177-2.

24. Skyttner, L. General Systems Theory: Problems, Perspectives, Practice, 2nd ed.; World Scientific: Hackensack, NJ, USA, 2005, ISBN 978-981-256-389-7.

25. Abramovitz, R.; Von Foerster, H. Cybernetics of Cybernetics: or, the Control of Control and the Communication of Communication; University of Illinois Press: Urbana, IL, USA, 1974.

26. Von Foerster, H. Understanding Understanding: Essays on Cybernetics and Cognition; 2-Pferdchen; Springer: New York, NY, USA, 2003, ISBN 978-0-387-95392-2.

27. Umpleby, S.A. Second-order cybernetics as a fundamental revolution in science. Constr. Found. 2016, 11, 455-465.

28. Umpleby, S.A. Second-order science: logic, strategies, methods. Constr. Found. 2014, 10, 16-23.

29. Fields, C. Building the Observer into the System: Toward a Realistic Description of Human Interaction with the World. In Second Generation General System Theory: Perspectives in Philosophy and Approaches in Complex Systems; Minati, G., Pessa, E., Licata, I., Eds.; MDPI AG: Basel, Switzerland, 2017; pp. 28-56, ISBN 978-3-03842-441-3.

30. Abundis, M. A priori modeling of information and intelligence. In Artificial General Intelligence; Everitt, T., Goertzel, B., Potapov, A., Eds.; Springer International Publishing: Cham, Switzerland, 2017; pp. 265-273.

31. Cottam, R.; Ranson, W.; Vounckx, R. Chaos and chaos; complexity and hierarchy. Syst. Res. Behav. Sci. 2015, 32, 579-592. [CrossRef]

32. Plato. Theatetus; Penguin Classics: Harmondsworth, Middlesex, UK; New York, NY, USA, 1987, ISBN 978-0-14-044450-6.

33. Dancy, J.; Sosa, E.; Steup, M. A Companion to Epistemology; Wiley-Blackwell: Malden, MA, USA, 2010, ISBN 978-1-4051-3900-7.

34. Gettier, E.L. Is justified true belief knowledge? Analysis 1963, 23, 121-123. [CrossRef]

35. Deacon, T.W. Information and reference. In Representation and Reality in Humans, Other Living Organisms and Intelligent Machines; Dodig-Crnkovic, G., Giovagnoli, R., Eds.; Springer International Publishing: Cham, Switzerland, 2017; pp. 3-15, ISBN 978-3-319-43784-2.

36. Hofkirchner, W. Emergent Information: A Unified Theory of Information Framework; World Scientific Publishing Co. Pte. Ltd.: Singapore, 2013, ISBN 978-981-4313-48-3.

37. Burgin, M. Theory of Information: Fundamentality, Diversity and Unification; World Scientific Publishing Co. Pte. Ltd.: Singapore, 2010, ISBN 978-981-283-548-2.

38. Floridi, L. The Philosophy of Information; Oxford University Press: Oxford, UK, 2010, ISBN 978-0-19-923238-3. 
39. Ibekwe-SanJuan, F.; Dousa, T.M. (Eds.) Theories of Information, Communication and Knowledge: A Multidisciplinary Approach; Springer: Dordrecht, The Netherlands, 2014; Volume 34, ISBN 978-94-007-6972-4.

40. Dodig-Crnkovic, G.; Burgin, M. Information and Computation: Essays on Scientific and Philosophical Understanding of Foundations of Information and Computation; World Scientific: Singapore, 2011, ISBN 978-981-4295-47-5.

41. Bateson, G. Steps to an Ecology of Mind: Collected Essays in Anthropology, Psychiatry, Evolution, and Epistemology; J. Aronson: Northvale, NJ, USA; London, UK, 1987, ISBN 978-0-87668-950-9.

42. Derrida, J. Différance. In Margins of Philosophy; University of Chicago Press: Chicago, IL, USA, 1984; pp. 1-28, ISBN 978-0-226-14326-2.

43. Van Dijk, T.A. Discourse Studies. A Multidisciplinary Introduction: Discourse as Structure and Process Volume 1; SAGE: London, UK, 1997, ISBN 978-0-8039-7844-7.

44. Fairclough, N. Analysing Discourse: Textual Analysis for Social Research; Routledge: London, UK, 2003, ISBN 978-0-415-25892-0.

45. Hyland, K.; Paltridge, B. Bloomsbury Companion to Discourse Analysis; Bloomsbury: London, UK; New York, NY, USA, 2011, ISBN 978-1-4411-6786-6.

46. Jørgensen, M.; Phillips, L. Discourse Analysis as Theory and Method; Sage Publications: London, UK; Thousand Oaks, CA, USA, 2002, ISBN 978-0-7619-7111-5.

47. Angermüller, J.; Maingueneau, D.; Wodak, R. An introduction. In The Discourse Studies Reader: Main Currents in Theory and Analysis; John Benjamins Publishing Company: Amsterdam, The Netherlands; Philadelphia, PA, USA, 2014, ISBN 978-90-272-1210-8.

48. Van Dijk, T.A. Discourse and knowledge. In The Routledge Handbook of Discourse Analysis; Routledge: London, UK, 2013; pp. 587-603, ISBN 978-0-415-70978-1.

49. Paltridge, B. Discourse Analysis: An Introduction; Continuum: London, UK; New York, NY, USA, 2006, ISBN 978-0-8264-8557-1.

50. Lyotard, J.-F. La condition postmoderne: rapport sur le savoir; Éd. de minuit: Paris, France, 1979, ISBN 978-2-7073-0276-2.

51. Audi, R. (Ed.) The Cambridge Dictionary of Philosophy, 2nd ed.; Cambridge University Press: Cambridge, UK, 1999, ISBN 978-0-521-63136-5.

52. George, R.; van Evra, J. The rise of modern logic. In A Companion to Philosophical Logic; Jacquette, D., Ed.; Blackwell Publishing Ltd: Malden, MA, USA, 2006; pp. 35-48, ISBN 978-0-470-99675-1.

53. Weik, M.H. Discourse universe. In Computer Science and Communications Dictionary; Weik, M.H., Ed.; Springer: Boston, MA, USA, 2001; p. 426, ISBN 978-1-4020-0613-5.

54. Frege, G. Philosophical and Mathematical Correspondence of Gottlob Frege, 1st ed.; McGuinness, B., Ed.; University of Chicago Press: Chicago, IL, USA, 1980, ISBN 978-0-226-26197-3.

55. Foucault, M. History of Madness; Khalfa, J., Ed.; Routledge: London, UK, 2006, ISBN 978-0-415-27701-3. 